Volume 1, Issue 2, Nov. - 2020: pp: 103-110 www.ejor.sohag-univ.edu.eg

Original article

\title{
BONE LENGTHENING IN CORRECTION OF HAND AND WRIST DEFORMITIES USING NEW MINI EXTERNAL FIXATOR
}

\author{
Hassan Noaman ${ }^{1(*)}$, Ahmed Addosooki ${ }^{1}$, Mohamed Ahmed $^{1}$, Fouad Assal $^{2}$, Abdullah Elsayed $^{1}$ \\ ${ }^{1}$ Orthopedic Surgery dept., Faculty of Medicine, Sohag University, Sohag, Egypt \\ ${ }^{2}$ Al Razi Hospital, Kuwait \\ *E-mail: hassan_h@mailcity.com
}

Received 7/9/2020

Accepted 9/11/2020

\begin{abstract}
Bone elongation through callotasis is a relatively simple procedure from a surgical point of view. Bone elongation results are amazing and highly beneficial to the patients 'life quality. A good use of the external fixation leads us to meet various orthopaedic and surgical techniques which were unthinkable years ago and which nowadays are a standard practice in pediatric and adult orthopaedics units worldwide. External fixation entails the use of percutaneously placed transosseus pins and/or wires secured to external scaffolding to provide support to a limb. The benefits of external fixation are numerous. When compared with internal plates and intramedullary nails, external fixators cause less disruption of the soft tissues, osseous blood supply, and periosteumin. Our task is to restore the anatomy of the locomotor system mechanically and, which is even more important, biologically, since the whole future life of these bones and joints will depend on it using new mini external fixator device manufactured and developed by Kuwait institute of science and research (KISR). Our study is a short term prospective study of patients received in emergency unit and orthopedic department at Sohag university hospital. After taking of written consent from the patients and approval of the ethical committee, 22 patients with posttraumatic or congenital wrist or hand deformities were treated by the new mini ex.fix. All patients were admitted to orthopedic trauma unit with hand and wrist deformities either traumatic or congenital and placed on radiolucent operating table. General anesthesia had been given to all patients. The new mini external fix technique should be considered for bone lengthening for the surgical treatment of Madelung 's and other hand and wrist deformities in patients suffering from persistent pain, deformity when gradual correction and lengthening is indicated as its easy for the patient and the operating surgeon with promising results.
\end{abstract}

Keyword: Bone lengthening, Hand and wrist deformities, Mini external fixator

\section{Introduction}

Bone elongation through callotasis is a relatively simple procedure from a surgical point of view. However, the large number of variables to consider when planning this type of treatment and their duration, which make them susceptible to many different complications, make it advisable to leave these cases in the hands of experts who know the obstacles they may find. Bone elongation results are amazing and highly beneficial to the patients' life quality [1]. A good use of the external fixation (in particular and in this case, the monolateral one) leads 
us to meet various orthopaedic and surgical techniques which were unthinkable years ago and which nowadays are a standard practice in paediatric and adult orthopaedics units worldwide. Circular external fixation is also very useful when necessary. Thus, the elongation of bones and their soft tissues (distraction osteogenesis and histogenesis) through external fixation is a method of treatment for various diseases that generates good results although it has difficulties. This guide aims to smooth the path for those who start using this technique, which seems simple but is highly complex in its background [2]. The technique of external fixation was popularized in the mid- $20^{\text {th }}$ century when Hoffman introduced a device that used Steinman pins and bars to stabilize long bone fractures [3]. Charnley concomitantly impressed the orthopedic community when he introduced an external fixator for knee arthrodesis. With a simple compression frame, he was able to dramatically increase knee fusion rates and decrease consolidation time [4]. Behrens described three basic concepts that govern the safe and effective application of external frames for bony trauma. The pins and wires should avoid damage to vital structures, allow access to the area of injury, and should meet the mechanical demands of the patient and the injury. While the

\section{Patients and Methods}

Our study is a short term prospective study of patients received in Emergency Unit and Orthopedic Department at Sohag University Hospital. The duration of the study was one year, between Jan 2019 and June 2020. After taking of written

\subsection{Pre-operative assessment}

A) History; include 1) Personal history (Name, Age, Sex and Occupation). 2) Past history (Details of previous disease or injury to the affected side, and previous operative procedures). 3) Etiology (Post traumatic, and congenital). B) Clinical exa-
Western world was using external fixators sparingly, external fixation was becoming a mainstay of orthopedic treatment in Russia and later in Northern Italy [5]. In Kurgan, Siberia, Professor Ilizarov found external frames to be invaluable for a myriad of applications including posttraumatic and congenital limb reconstruction, limb salvage, complex arthrodesis, management of osteomyelitis and bone defects, and deformity correction [6]. Using a circular fixation design with simple and versatile components, he was able to develop a method for osteogenesis that relied on a percutaneous approach with minimal trauma to the limb, closed anatomic fracture reduction, and excellent bony stability that allowed early weight bearing [7]. In fast growing field of limb lengthening and limb reconstruction, external fixators are powerful tools that enable surgeons to carry out the Ilizarov method and provide solutions to many difficult musculoskeletal problems, external fixators cause less disruption of the soft tissues, osseus blood supply, and periosteumin [8]. Our task is to restore the anatomy of the locomotor system mechanically and, which is even more important, biologically, since the whole future life of these bones and joints will depend on it.

consent from the patients and approval of the ethical committee, 22 patients with posttraumatic or congenital wrist or hand deformities were treated by the new mini ex fix.

mination include 1) General examination. 2) Skin condition. 3) Neurovascular complications. C) Investigations include 1) Routine Laboratory tests. 2) Radiological evaluation (plain X-rays; standard AP and lateral views). 


\subsection{Operative procedure}

After pre-operative investigations $\&$ assessment by pre-anesthetic clinic, the patients were placed on radiolucent

\subsection{Surgical technique}

The surgical technique includes: *) Metaphyseal osteotomy. *) Respect to the surrounding tissues, and especially the periosteum. *) Control of thermal necrosis of the bone. *) Latency period to allow the

\subsection{Postoperative management}

Pain should be controlled through oral or injection analgesics. It is important that the patient suffers little pain, especially if we can anticipate that he/ she will be subjected to subsequent elongations. Nevertheless, some drugs such as diclofenac-derived NSAIDs are not recommended since they can inhibit new bone formation. Other commonly used analgesics have not shown adverse effects related to osteogenesis. Lengthening is done manually with the mini external fixator device within 5 days postoperatively. The rate is approximately one millimeter $(\mathrm{mm})$ per day, but may be slower or faster depending on the tolerance of the bone and soft tissues. To make the lengthening gentler, the one millimeter per

\section{Results}

Bone lengthening by distraction osteogenesis was done to 22 patients (15 post-traumatic and 7 congenital) aged between 3 years to 60 years old, $\operatorname{tab}_{\mathrm{s}}(1$ $\&$ 2). All patients were reviewed at a mean 15 weeks ( 12 wks-18 wks). Mean lengthening was $2.7 \mathrm{~cm}(1.62 \mathrm{~cm}-3.8$ $\mathrm{cm})$. The date the lengthening was started varied according to several criteria: pain intensity, time until good-quality postoperative radiographs were obtained so that the correction program could be calculated, and the patient's pathology, operating table. General anesthesia had been given to all patients.

organisation of the callus. *) Phase of gradual and controlled distraction. *) Neutralisation phase to facilitate callus ossification. *) Dynamisation phase to help the corticalization of the regeneration.

day is broken into half millimeter increments. Parents and patients are taught to turn the distraction rod on the external fixator one half turn $(1 / 2 \mathrm{~mm})$ twice per day. The lengthening causes an increase in the tension of the soft tissues, and this tension increases with the length. Muscle tension reaches its top at the end of the distraction period. During the neutralisation, it begins to decline, facilitating the joint movements. To address musculo tendinous contractures, using active physiotherapy throughout treatment to prevent them is the most interesting strategy. Radiograhic follow up with $\mathrm{x}$-ray imaging during the distraction phase on weekly basis and 2-3 weeks during consolidation phase.

restoration of function and range of motion analysis of the follow-up radiographs of the series demonstrated that there was no residual deformity. Pin tract infections were present in one case was successfully managed with correct pin care and oral or parenteral administration of antibiotics when necessary. Another case reported delayed healing due traumatic fracture during the process of healing. All cases show good power and pinch grip with excellent function and cosmetic appearance. 
Table (1) Lengthening of metacarpal bone

\begin{tabular}{|c|c|c|c|c|c|c|c|}
\hline $\begin{array}{c}\text { Cases } \\
\text { No. }\end{array}$ & Sex & Age & $\begin{array}{l}\text { Etiology of } \\
\text { deformity }\end{array}$ & $\begin{array}{l}\text { Type of Deformity, } \\
\text { Lengthening of }\end{array}$ & $\begin{array}{c}\text { Lengthening in } \\
\text { cm / Duration of } \\
\text { lengthening }\end{array}$ & Complications & $\begin{array}{l}\text { Functional } \\
\text { improvement in the } \\
\text { hand }\end{array}$ \\
\hline $\mathbf{1}$ & F & 14 & Post-traumatic & $\begin{array}{c}\text { Amputation Rt. Thumb } \\
\text { Lengthening of } 1^{\text {s }} \\
\text { MCB }\end{array}$ & $3 \mathrm{~cm} / 13$ weeks & No & $\begin{array}{l}\text { Good power and pinch } \\
\text { grip }\end{array}$ \\
\hline 2 & $\mathbf{M}$ & 24 & Post-traumatic & $\begin{array}{c}\text { Amputation Lt Thumb } \\
\text { Lengthening of } 1^{\text {s }} \\
\text { MCB }\end{array}$ & $3.4 \mathrm{~cm} / 14$ weeks & $\begin{array}{c}\text { Contracted } 1^{\text {s }} \\
\text { web due to skim } \\
\text { graft }\end{array}$ & $\begin{array}{l}\text { Good power and pinch } \\
\text { grip after opening of } \\
\text { the web space by } \\
\text { traction using ex.fix }\end{array}$ \\
\hline 3 & $\mathbf{M}$ & 32 & Post-traumatic & $\begin{array}{c}\text { Amputation Lt Thumb } \\
\text { Lengthening of } 1^{\text {s }} \\
\text { MCB }\end{array}$ & $3.5 \mathrm{~cm} / 14$ weeks & No & $\begin{array}{l}\text { Good power and pinch } \\
\text { grip }\end{array}$ \\
\hline 4 & $\mathbf{M}$ & 56 & $\begin{array}{l}\text { Post-traumatic } \\
\text { (crush injury) }\end{array}$ & $\begin{array}{l}\text { Amputation Rt Thumb } \\
\text { and all fingers except } \\
\text { middle finger } \\
\text { Lengthening of } 1^{\text {st }} \\
\text { MCB }\end{array}$ & $3.8 \mathrm{~cm} / 14$ weeks & No & $\begin{array}{c}\text { Good power and pinch } \\
\text { grip }\end{array}$ \\
\hline 5 & $\mathbf{M}$ & 36 & Post-traumatic & $\begin{array}{c}\text { Amputation Rt Thumb } \\
\text { Lengthening of } 1^{*} \\
\text { MCB }\end{array}$ & $3.2 \mathrm{~cm} / 14$ weeks & No & $\begin{array}{l}\text { Good power and pinch } \\
\text { grip }\end{array}$ \\
\hline 6 & $\mathbf{M}$ & 28 & Post-traumatic & $\begin{array}{l}\text { Amputation Lt Thumb } \\
\text { Lengthening of } 1^{\text {* }} \\
\text { MCB }\end{array}$ & $3 \mathrm{~cm} / 14$ weeks & $\begin{array}{l}\text { Superficial } \\
\text { inflammation } \\
\text { which treated } \\
\text { successfully }\end{array}$ & $\begin{array}{c}\text { Good power and pinch } \\
\text { grip }\end{array}$ \\
\hline 7 & F & 19 & congenital & $\begin{array}{l}\text { Shortening of the } 4^{\text {th }} \\
\text { MCB of both hands } \\
\text { Lengthening of Rt and } \\
\text { Lt } 4^{\text {th }} \text { MCB }\end{array}$ & $\begin{array}{c}\text { Rt hand } \\
1.92 \mathrm{~cm} / 13 \\
\text { weeks } \\
\\
\text { Lt hand } \\
1.62 \mathrm{~cm} / 18 \\
\text { weeks }\end{array}$ & $\begin{array}{c}\text { Rt. No } \\
\text { Lt. Delayed } \\
\text { healing due to } \\
\text { fracture }\end{array}$ & $\begin{array}{c}\text { Both hand } \\
\text { Cosmetically } \\
\text { improving with good } \\
\text { R.O.M im both mcph } \\
\text { joint }\end{array}$ \\
\hline
\end{tabular}

Table (2) Wrist deformity due to radial bone shortening

\begin{tabular}{|c|c|c|c|c|c|c|c|}
\hline $\begin{array}{c}\text { Cases } \\
\text { No. }\end{array}$ & Sex & Age & $\begin{array}{c}\text { Etiology of } \\
\text { deformity }\end{array}$ & $\begin{array}{c}\text { Type of Deformity } \\
\text { Lengthening of }\end{array}$ & $\begin{array}{c}\text { Lengthening in cm } \\
\text { /Duration of } \\
\text { lengthening }\end{array}$ & Complications & $\begin{array}{c}\text { Functional } \\
\text { improvement in } \\
\text { the hand }\end{array}$ \\
\hline 1 & $\mathrm{M}$ & 14 & Post-traumatic & $\begin{array}{c}\text { Posttraumatic radial } \\
\text { shortening ( radial } \\
\text { growth arrest) with } \\
\text { wrist deviation }\end{array}$ & $\begin{array}{c}\text { Lengthening of the } \\
\text { Lt radius } \\
2.8 \mathrm{~cm} / 15 \text { weeks }\end{array}$ & No & $\begin{array}{c}\text { Correction of the } \\
\text { wrist deformity } \\
\text { with excellent } \\
\text { functionally and } \\
\text { cosmetic result }\end{array}$ \\
\hline 2 & $\mathrm{M}$ & Congenital & $\begin{array}{c}\text { Radial club hand } \\
\text { (bilateral) } \\
\text { Partial absence of the } \\
\text { radius, wrist deviated } \\
\text { with fimger deformity }\end{array}$ & $\begin{array}{c}\text { Lengthening of the } \\
\text { Rt radius } \\
2.44 \mathrm{~cm} / 12 \text { weeks } \\
\text { Lengthening of the } \\
\text { Lt radins } \\
\text { wrist deformity } \\
\text { For good } \\
\text { improvement of the } \\
\text { function the pt will } \\
\text { be operated for } \\
\text { separation of the } \\
\text { thumb and fmgers }\end{array}$ \\
\hline
\end{tabular}

\section{Discussion}

External fixator types divide into several different subcategories, including uniplanar, multiplanar, unilateral, bilateral, and circular fixators. By adding pins in different planes (i.e., placed perpendicular to each other), one can create a multiplanar construct. Uniplanar fixation devices are fast and easy to apply but are not as sturdy as multiplanar fixation. Bilateral frames are created when the pins are on both sides of the bone and can also add additional stability. Circular fixators have gained popularity with limb lengthening procedures but are especially effective at allowing the patient to weight bear and maintain some joint motion during the treatment. They are more difficult to apply and use smaller gauge pins and more of them to distribute the weight. There are many different ways to change and enhance the external fixation construct. To complicate things further, there are also hybrid frames which are a combination of any of the previous constructs described. The surgeon must create a level of stability that is appropriate for optimal healing. It is essential also to have a good understanding of basic fracture principals because stiffer 
is not always better when it comes to external fixation. In this thesis we introduce a new mini external fixator device that been used for bone lengthening for correction of various hand and wrist deformities that was designed by hand surgeon's-Alrazi hospital Kuwait and manufactured by Kuwait institute of science and research KISR. For numerous surgical indications (congenital or acquired or posttraumatic conditions of upper extremity) * Achondroplasia. * Radial or Ulnar longitudinal deficiency. * Multiple hereditary exostosis. * Brachymetacarpia. * Symbrachydactyly. * Post-traumatic and post-infectious growth arrest. * Metacarpal lengthening in cases of traumatic (thumb) bone loss [9]. Unilateral frames are distinguished from circular frames in that they are positioned on one side of the limb. Unilateral frames allow the limb to remain functional, avoid complications, and provide bony stability. When we consider unilateral frames, the two most common designs are the bulkier monobody designs (EBI, Parsippany, NJ, USA, and Orthofix, Verona, Italy) and the trauma type pin-to-bar fixators. (A word on hybrid external fixators: Hybrid fixators are unilateral fixators with a ring attached and behave like monobody designs. Hybrid fixation also refers to the substitution of half pins for some wires when using an Ilizarov ringed fixator, a technique developed in Italy. In this report, all references to hybrid fixation refer to the Italian definition.) The stability of all unilateral frames is improved by the use of larger-diameter half pins with more points of fixation, decreasing the distance between the frame and the bone, and placing pins out-of-plane to one another. The monobody frames have considerable intrinsic stability owing to their heavy and rigid design. Most pin-to-bar designs use multiple lightweight carbon fiber rods to provide stability. Improved rigidity of these fixators is obtained by adding a second connecting rod to the same pins and by adding a second half-frame in a different plane to the first. These fixators are versatile enough to allow pins to be placed both near to the fracture and far from the fracture providing excellent control of the bone segment. During surgery, small incisions will be made and then insert pins or wires into the bone. The external fixator frame will be attached to these pins and wires and secured using clamps and rods. If the bone is to be lengthened or straightened, the doctor will then surgically cut the bone (osteotomy) to create two separate bone segments. Procedural success will depend greatly on the correct indication of it, as well as of the proper planning of all the parameters that configure the deformity. Anthropometric tables will be used to calculate the percentage ratios between the height and the length of the long bones of the upper and lower extremities measured on radiographs of normal individuals of the age and gender of the patient. Clearly, a complete analysis of the medical history of the patient must be conducted. This will identify possible an aesthetic risks or risks during the surgery or the treatment for planning purposes, it is essential to have anteroposterior and axial radiographs. Clinical photographs may be helpful to know the aesthetic effects that the bone deformities make on the external appearance, and for comparative purposes at completion of the treatment. Callotasis is the technique of bone elongation developed by the Orthopaedic Institute of Verona (De Bastiani, Aldegheri, Renzi-Brivio and Trivella) based on a set of principles that seek to obtain an indistinguishable bone regeneration of the patient's healthy bone and minimising the complications of the procedure. The basis of the technique are: * Metaphyseal osteotomy. * Respect to the surrounding tissues, and especially the periosteum. * Control of thermal necrosis of the bone. * Latency period to allow the organisation of the callus. * Phase of gradual and controlled distraction. * Neutralisation phase to facilitate callus ossification. * Dynamisation phase to help the corticalization of the regeneration. After surgery, the bones are allowed to rest for 5 to 7 days to begin the healing process. After this period of time, the distraction phase of treatment begins. The patient (or family 
member) will be given a schedule that instructs them how to adjust the fixator several times a day by turning small knobs or other parts of the device to slowly pull the bone segments apart. This gradual process of slowly separating the bone segments is called distraction, which means; pulling apart. As the bone segments are pulled apart at a slow rate of approximately $1 \mathrm{~mm}$ (0.04 inches) per day, new bone forms in the space between them. The new bone is called regenerate bone. The distraction phase lasts until the bone is straight or corrected. The patient will need to see the doctor every 10 to 14 days during the distraction phase. After the correction has been achieved, the consolidation phase begins in which the regenerate bone slowly hardens. During this phase of treatment, the external fixator normally remains in place so that it can support the bone as it heals. The bone has consolidated (-healed) when the regenerate bone has completely hardened and calcified. The consolidation phase typical takes twice as long as the distraction phase.
For example, if distraction is completed in 1 month, then consolidation will take 2 months. In this example, the external fixator would remain on the patient for a total of 3 months through both the distraction and consolidation phases. After the bone is fully consolidated, the external fixator can be removed during an outpatient surgical procedure [10]. In our practice, most infections respond well to aggressive local pin care and empiric oral antibiotics. If the infection does not resolve quickly, then culture-specific antibiotics are used. More advanced infections are aggressively treated with removal of the pin or wire. Cellulitis is treated with intravenous antibiotics. Rarely, operative intervention is needed for pin infections to replace an important pin or debride osteomyelitic bone. Historically, malunion has been a commonly reported complication for fracture treatment with fixators, but this has not been the case in our practice. Septic arthritis may complicate any patient being treated with fixators [11].

\section{CONCLUSION}

The new mini external fix technique should be considered for bone lengthening for the surgical treatment of Madelung's and other hand and wrist deformities in patients suffering from persistent pain when gradual correction and lengthening is indicated as its easy for the patient and the operating surgeon with promising results.

\section{Reprehensive Case (Wrist deformity due to radial bone shortening)}

This case represents a 14 years old Radial growth arrest with wrist deviation, boy with post traumatic radial shortening. fig. (1)

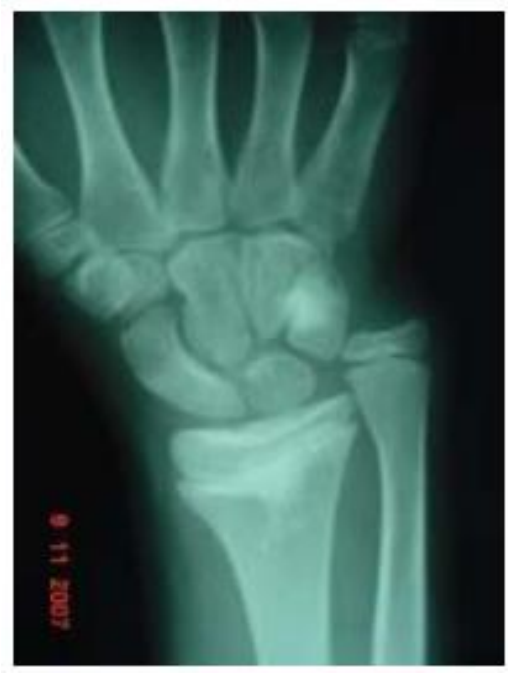

Figure (1) radial growth arrest with wrist deviation 


\subsubsection{Operative technique}

* Using simple Ex. Fix without double distraction effect. * Insertion of 2 pins in the $2^{\text {nd }} \& 3^{\text {rd }} \mathrm{MCB}$, fig. (2). * Insertion of 2 pins in the distal end radius. * Insertion of 2 pins in the distal end radius. * Radial osteotomy. * According to
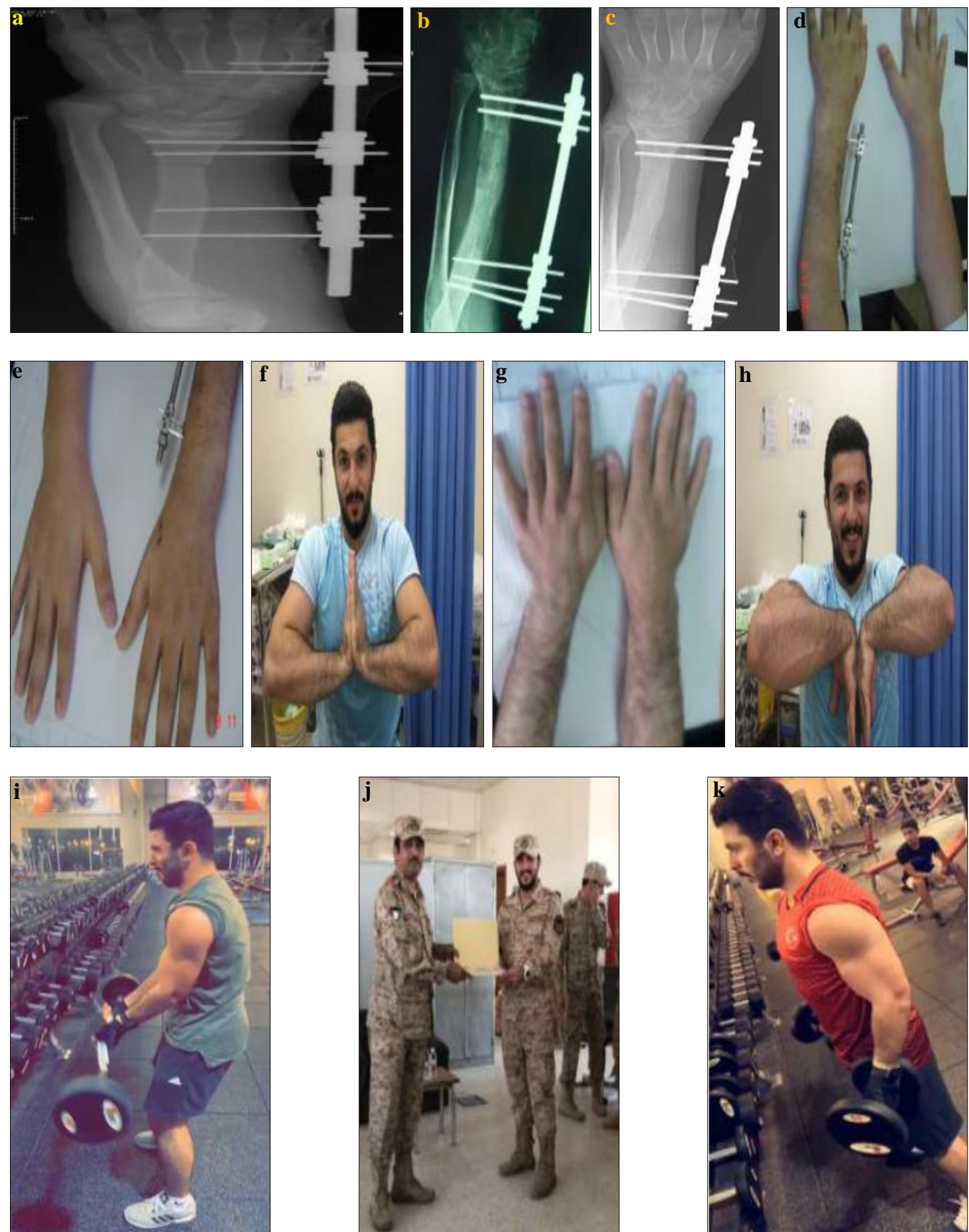

Figure (2) Shows a. immediate postoperative X-ray, b. after reaching the required length, the pins were removed and the device shorted to start e early movement in the wrist joint, c. full consolidation after 14 weeks, d. good correction of the deformity, e. before removal of the

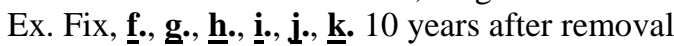




\section{References}

[1] Wiedemann, M. (1996). Callus distraction: A new method? A historical review of limb lengthening. Clin Orthop Relat Res. 327: 291-304.

[2] Fragomen, A., Robert Rozbruch, S. (1994). External fixation entails the use of percutaneously placed transosseus pins and/or wires secured to external scaffolding to provide support to a limb. In this way, a bone or joint can be stabilized in the setting of trauma or limb reconstruction. J. of Pediatric Orthopaedics B. 3: 11-15.

[3] Hierner, R., Wilhelm, K., Brehl, B. (1998). Callus distraction for lengthening of mid-hand and finger stumps in congenital hand abnormalities-personal results and review of the literature. Handchir Mikrochir Plast Chir. 30 (3): 196-205.

[4] Cattaneo R, Catagni M, Guerreschi F. (2001). Treatment of radial agenesis with the Ilizarov method. Rev Chir Orthop Reparatrice Appar Mot. 87 (5): 443-450.

[5] Valenti D, Salazard B, Samson P, et al. (2006). Bone lengthening by distraction of the metacarpal or phalanx in children. Chir Main. 25 (6): 298-302.

[6] Houshian, S., Jorgsholm, P., Friis, M., et al. (2000). Madelung deformity treated with Ilizarov technique: A report of two cases. J Hand Surg Br. 25 (4): 396-399.

[7] Rozburch, Sr., Birth, J., Dahl, M., et al. (2014). Motorized intramedullary nail for management of limb- length discrepancy and deformity. J Am Acad Orthop Surg. 22 (7): 403-409.

[8] Popkov, D., Popkov, A., Haumont, T., et al. (2010). Flexible intramedullary nail use in limb lengthening. $\boldsymbol{J}$ Pediatr Orthop. 30 (8): 910-918.

[9] Malot, R., Park, K., Song, SH. (2013). Role of hybrid monolateral fixators in managing humeral length and deformity correction. Acta Orthop. 84: 280-285.

[10] Bibbo, C., Brueggeman, J. (2010). Pin site infection is a common complication of external fixation. I: Prevention and management of complications arising from external fixation pin sites. The Journal of Foot \& Ankle Surgery. 49 (1):87-92

[11] Manggala, Y., Chayanin Angthong, C., Primadhi, A., et al. (2017). The deformity correction and fixator assisted treatment using Ilizarov versus Taylor spatial frame in the foot and ankle. Orthop Rev. 9 (4): 7337. 